Bangladesh J. Bot. 50(3): 911-916, 2021 (September) SpecialＤOI: https://doi.org/10.3329/bjb.v50i5.56444

\title{
EFFECTS OF BIO-ORGANIC FERTILIZERS ON SOIL ORGANIC CARBON COMPONENTS AND BIOMASS OF SHAMROCK
}

\author{
Tingting Meng ${ }^{1,2,3,4}$ AND JinBaO LiU ${ }^{1,2,3,4 *}$ \\ Shaanxi Provincial Land Engineering Construction Group Co. Ltd, \\ Xi'an, Shaanxi,710075, China
}

Keywords: Bio-organic fertilizer, Organic carbon composition, Shamrock, Aboveground biomass, Underground biomass

\begin{abstract}
Effects of bio-organic fertilizer to organic carbon (SOC), dissolved organic carbon (DOC), easy oxidation of organic carbon (ROC), microbial biomass carbon (MBC) and Shamrock biomass were studied. The results showed that the contents of SOC, DOC, ROC, MBC could be significantly increased by bioorganic fertilizer. When cultured for 180d, SOC and DOC increased by 42 154 and 9 40\%, respectively, compared with T0 treatment. ROC and MBC content increased by 38 173 and 4 9\%, respectively. In addition, with the increase of the application of bio-organic fertilizer, the SOC and DOC contents increased. In T4 treatment, the SOC and DOC contents were the highest, which were $25.05 \mathrm{~g} / \mathrm{kg}$ and $74.89 \mathrm{mg} / \mathrm{kg}$, respectively. In T3 treatment, the ROC and MBC contents were the highest, $9.84 \mathrm{~g} / \mathrm{kg}$ and $167.09 \mathrm{mg} / \mathrm{kg}$, respectively. Compared with the initial incubation period, SOC decreased by $6 \sim 17 \%$, DOC increased by $3 \sim 13 \%$, ROC and MBC increased by 15 64, 3 25\%, respectively. The application of bio-organic fertilizer increased the aboveground and underground biomass and the highest value were in the T2 and T3 treatments, respectively. The application of biological organic fertilizer increased the content of active organic carbon components. Results of the present study provide evidence for the application of biological organic fertilizer in the agricultural area of China.
\end{abstract}

\section{Introduction}

Organic fertilizer is a kind of fertilizer produced by fermenting animal manure and plant litter as a substrate. It is rich in organic matter and nutrients. Reasonable application of organic fertilizer can significantly improve the physical and chemical properties of poor soil and crop properties, thereby solving soil fertilizer efficiency, water and fertilizer leakage, improve crop production capacity, and ultimately increase agricultural production (Halen et al. 2003, Zhang et al. 2009). Bio-organic fertilizer is a new type of organic fertilizer derived from adding certain beneficial microorganisms on this basis. Compared with ordinary organic fertilizers, bio-organic fertilizers are also rich in beneficial microorganisms and functional bacteria such as yeast, lactic acid bacteria, cellulose decomposing bacteria and nitrogen-fixing bacteria. The existence of these microorganisms can effectively improve the root soil environment and improve the soil more significantly (Schlegel 1992, Aggelides and Londra 2000, Egashira et al. 2003).

Soil organic carbon (SOC) characterizes the size and quality of soil fertility (He et al. 2015). According to the existence and stability of organic carbon, organic carbon can generally be divided into active organic carbon and stable organic carbon. Soil active organic carbon is dominated by dissolved organic carbon (DOC), easily oxidizable organic carbon (ROC) and

*Author for correspondence:< jinbaoliu@xaut.edu.cn>. ${ }^{1}$ Institute of Land Engineering and Technology, Shaanxi Provincial Land Engineering Construction Group Co., Ltd., Xi'an, China. ${ }^{2}$ Key Laboratory of Degraded and Unused Land Consolidation Engineering, Ministry of Land and Resources, Xian, China. ${ }^{3}$ Shaanxi Provincial Land Consolidation Engineering Technology Research Center, Xi' an, China. ${ }^{4}$ Land Engineering Technology Innovation Center, Ministry of Natural Resources. Xian, China. 
microbial biomass carbon (MBC). The active organic carbon in the soil that moves fast, has poor stability, is easy to oxidize, and is easy to mineralize, and is often used as an index for evaluating soil quality (Dumale et al. 2009). The long-term fertilization experiment of Sleutel et al. (2006) showed that the combined application of N, P, and K fertilizer with organic fertilizer can increase crop yield. Research done by Yousefi et al. (2008) showed that as the amount of organic fertilizer increases, the stability of soil aggregates, organic carbon, water-soluble organic carbon (DOC), and the content of weak acid hydrolysis compounds further increase. The research results of $\mathrm{Li}$ et al. (2018) showed that the application of organic fertilizer increased organic carbon and active components (DOC and LFOC). The active components of soil organic carbon are very sensitive to change in the external environment, and can reflect the dynamic changes of soil organic carbon by fertilization methods and amounts in a timely manner (Ding et al. 2006).

Loutu is one of the main production soils in the Guanzhong area of Shaanxi Province, accounting for $34.1 \%$ of the cultivated land in Shaanxi Province. In order to increase the content of organic matter in the Loutu and improve soil fertility, and to increase crop yield and efficiency, organic and inorganic fertilizers are often used, and soil amendments are combined with organic and inorganic fertilizers. However, with the application of different organic fertilizers, the changing trend of the organic carbon components of loess soil is still not clear. Therefore, in this study $t$ loess soil in the Guanzhong area was taken as the test materials. In the clover pot cultivation simulation experiment, different quality on bio-organic fertilizers were applied to the loess soil for a certain period of cultivation to study and analyze the change in organic carbon components in the loess soil and the clover biomass, to provide a scientific basis for the rational management of highland soil and efficient planting of crops.

\section{Materials and Methods}

The experiment farmland loess soil of Chuyuan Village (10811'E, 34 $42^{\prime} \mathrm{N}$ ) in Fuping, Shaanxi Province was used as the test material. The bio-organic fertilizer (884) produced by Hebei Dewoduo Fertilizer Co., Ltd., with organic matter content $>40 \%$; microbial viable bacteria $>100$ million/g was adopted. White clover seeds were selected, and the experiment was carried out in the greenhouse of the Qinling Field Monitoring Center Station. The basic physical and chemical indexes of the tested loess and bio-organic fertilizer are shown in Table 1.

Table 1. Basic physical and chemical properties of tested loess soil and bio-organic fertilizer.

\begin{tabular}{lcccccc}
\hline Material & $\mathrm{pH}$ & $\begin{array}{c}\text { Organic } \\
\text { matter }(\mathrm{g} / \mathrm{kg})\end{array}$ & $\begin{array}{c}\text { Total } \\
\text { nitrogen } \\
(\mathrm{g} / \mathrm{kg})\end{array}$ & $\begin{array}{c}\text { Total } \\
\text { phosphorus } \\
(\mathrm{g} / \mathrm{kg})\end{array}$ & $\begin{array}{c}\text { Available } \\
\text { phosphorus } \\
(\mathrm{mg} / \mathrm{kg})\end{array}$ & $\begin{array}{c}\text { Quick-acting } \\
\text { potassium } \\
(\mathrm{mg} / \mathrm{kg})\end{array}$ \\
\hline $\begin{array}{l}\text { Loutu } \\
\begin{array}{l}\text { Bio-organic } \\
\text { fertilizer }\end{array}\end{array}$ & 7.3 & 16.21 & 0.51 & 0.74 & 12.3 & 124 \\
\hline
\end{tabular}

The experiment was conducted in indoor pot cultivation method, setting 0 (T0), $10 \mathrm{~g} / \mathrm{kg}$ (TI), $20 \mathrm{~g} / \mathrm{kg}$ (T2), $30 \mathrm{~g} / \mathrm{kg}$ (T3), $40 \mathrm{~g} / \mathrm{kg}$ (T4) with 5 bio-organic fertilizers application level. Each treatment was repeated 3 times and a total of 15 pot experiments were set up. Each flowerpot contained $500 \mathrm{~g}$ of soil + organic fertilizer (passed through a $2 \mathrm{~mm}$ sieve). The organic fertilizer was mixed with the soil according to the set amount and added it to the flowerpot evenly. Water was added to $70 \%$ of the field water holding capacity to make the soil fully moist. Treated clover seeds ( 5 to 8 ) were sprinkled on the soil, and they were planted 2 weeks after the clover emerges. 
Seeds were left in each pot and kept in the greenhouse. During the cultivation period, the soil moisture was kept to the level by weighing. $70 \%$ of field water holding capacity.

On the 90th, 120th, 150th, and 180th days of culture, a soil drill was used with a diameter of 2 $\mathrm{cm}$ in each flowerpot, evenly taken 3 soil samples, mixed them as a soil sample, after natural air drying, grinded and paned through 2 and $0.149 \mathrm{~mm}$ sieves. SOC was determined by potassium permanganate external heating method (Bao 2005), DOC was determined by total organic carbon analyzer (Bao 2005), ROC was determined by $\mathrm{K}_{2} \mathrm{MnO}_{4}$ oxidation method-colorimetric method (Bao 2005), MBC was determined by chloroform fumigation $-\mathrm{K}_{2} \mathrm{SO}_{4}$ solution extraction method (Bao 2005). On the 180th day, the biomass on the clover grass was harvested, treated in an oven, dried and weighed.

Data processing uses excel 2010, one-way analysis of variance uses SPSS 22.0, and LSD method were used to test the significance of the difference $(\mathrm{p}<0.05)$, and the drawing uses Origin 2018.

\section{Results and Discussion}

From Fig.1a, b, it is apparent that under different application rates of bio-organic fertilizer, the content of SOC and DOC was $\mathrm{T} 4>\mathrm{T} 3>\mathrm{T} 2>\mathrm{T} 1>\mathrm{T} 0$, that is, the application of bio-organic fertilizer can increase the content of SOC and DOC. And with the increase of the amount of bioorganic fertilizer, there were significant differences between the treatments in each culture stage (p $<0.05$ ). When cultured to 180 days, compared with T0 treatment in T1 T4 treatment SOC and DOC content increased by 42 154\%, respectively. In the T4 treatment SOC and DOC contents were the highest. Compared with the initial stage of the culture, the SOC content of each treatment was reduced by 6 to 17\%. In the T4 treatment, there was a significant difference between the initial stage and the later stage of the culture. In other treatments in each culture the time period difference was not significant. The DOC content showed an increasing trend with the extension of the culture time, compared with the initial stage of the culture, the DOC content increased by 3 to $13 \%$ in each treatment. When $\mathrm{T} 1$ and $\mathrm{T} 2$ were treated, the DOC content was significantly different in each culture period ( $p<0.05$ ), but in T3 and T4 treatments, significant differences were found only in the early and late stages of culture.

Figure 1c, d, reveals that the ROC and MBC contents under different application rates of bioorganic fertilizer were $\mathrm{T} 3>\mathrm{T} 4>\mathrm{T} 2>\mathrm{T} 1>\mathrm{T} 0$, that is, the application of bio-organic fertilizer can increase the content of ROC and DOC at the same time. With the increase in the amount of bioorganic fertilizer, the content of ROC and MBC increased first and then decreased. When the T3 treatment was exceeded, the content of ROC and MBC decreased, but it was greater than that of the CK treatment. The treatments were significant in each culture stage difference $(p<0.05)$. When cultured to 180 days, compared with T0 treatment in T1 T4 treatment, ROC and MBC content increased by 38 173, 4 9\%, respectively. With the extension of culture time, the content of ROC and MBC increased. Compared with the initial stage of culture, the content of ROC and MBC increased by 15 64 and 3 25\%, and there were significant differences between the treatments at the last stage of the culture and the previous stage. The ROC content was $150 \mathrm{~d}$, the content was the highest, and when the MBC content was 180d, the content was the maximum.

Figure 2(a) reveals that the aboveground biomass of clover in each treatment was significantly higher than that in $\mathrm{T} 0$ at the first (90 days) harvest. There were no significant differences among $\mathrm{T} 2$, T3 and T4 treatments, but they were all significantly higher than T1. At the second harvest (180 days), the biomass of all treatments was higher than that of the first, and the biomass of T2 treatment was the highest, but there was no significant difference between T3 and T4 treatments. 

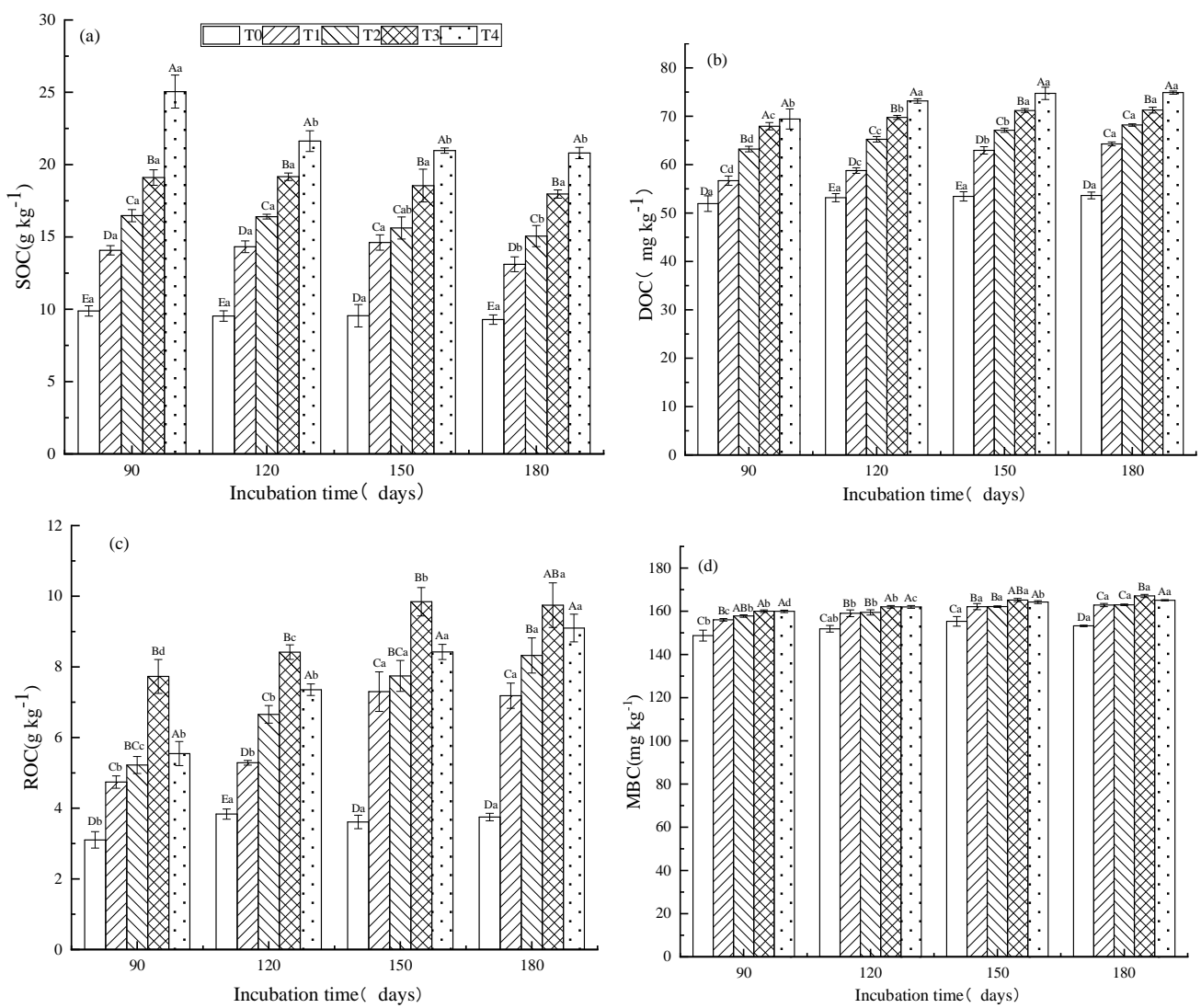

Fig. 1. Effect of application rate of bio-organic fertilizer on soil organic carbon components, SOC(a), $\mathrm{DOC}(\mathrm{b}), \mathrm{ROC}(\mathrm{c})$ and $\mathrm{MBC}(\mathrm{d})$. Lowercase letters indicate the differences between the various incubation times under the same treatment, and uppercase letters indicate the differences between the various treatments during the same incubation period.

The biomass of clover grassland was significantly higher than $\mathrm{T} 0$ in all the treatments at the first harvest (90 days), and the highest value was in T3 treatment and it was significantly different from T1, T2 and T4 (Fig. 2b). At the second harvest (180 days), there was little difference between the treatments and the first harvest. All treatments were significantly higher than T0, and the highest value was at $\mathrm{T} 4$.

The content of soil organic carbon active components (SOC, DOC, ROC and MBC) treated with bio-organic fertilizer was significantly increased, which is consistent with the results of previous studies (Chen et al. 2014, Tian et al. 2015). Bio-organic fertilizer brings exogenous organic carbon into the soil and promotes the increase of various components of soil organic carbon. At the same time, as a functional bacterial fertilizer, bio-organic fertilizer contains a variety of beneficial microorganisms, which can increase the population and number of microorganisms in the soil. Under each treatment, the SOC content showed a decreasing trend with the extension of time, and the content of DOC, ROC and MBC showed an increasing trend with the extension of the cultivation time. The reason is that with the extension of time, the microbial fertilizer was decomposed and the inert carbon was decomposed. It becomes activated carbon, so the active components of organic carbon increase, while the total amount of organic 
carbon decreases. The content of soil organic carbon is greatly affected by climate, especially the hydrothermal conditions of the soil and the nature and intensity of physical and chemical processes. Generally, as a large area, the content of soil organic matter should be relatively stable. However, as a small area, with sufficient organic fertilizer resources and higher organic matter content, the more organic fertilizer is applied to the soil, the higher the soil organic carbon content increased. Therefore, in a small area of potted soil, the more organic fertilizer was applied, the higher the SOC and DOC content was found. In the T3 treatment, the ROC and MBC contents were the highest, and Shamrock had the highest biomass indicating that the amount of bio-organic fertilizer used in the $\mathrm{T} 3$ treatment could better improve the soil fertility status.
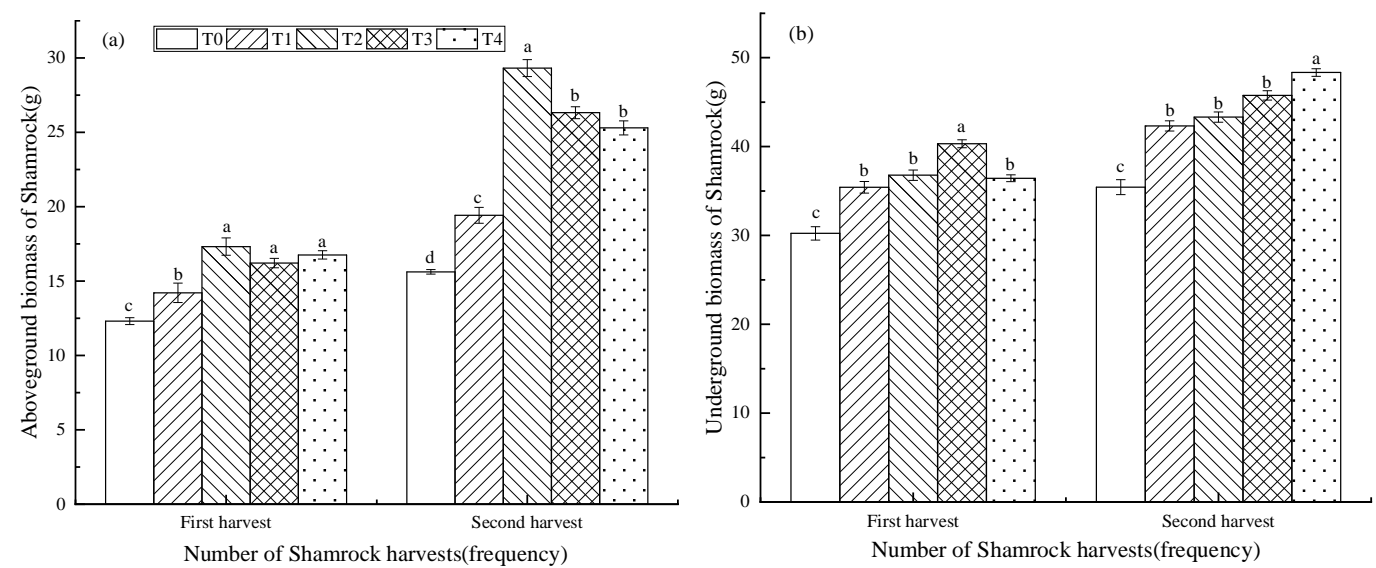

Fig. 2. Aboveground (a) and underground (b) biomass of Shamrock. Different lowercase letters indicate significant differences in Shamrock biomass between treatments $(\mathrm{p}<0.05)$.

The application of bio-organic fertilizer significantly increased the content of active components of organic carbon in the loess soil. When the application rate was $30 \mathrm{~g} / \mathrm{kg}$, the content of ROC and MBC in the loess soil was the highest and the biomass on the Shamrock grassland also was the highest. A certain amount of bio-organic fertilizer can be appropriately applied in the actual production of loess soil in Guanzhong area of Shaanxi to improve the fertility and productivity of loess soil. The present study is an indoor simulated cultivation experiment. The soil environment is small and the fertilizer is sufficient, which is different from the actual field soil environment. Therefore, the optimal application amount of bio-organic fertilizer in actual production might have a certain gap with this result.

\section{Acknowledgements}

This work was financially supported by Shaanxi Provincial Land Engineering Construction Group fund (DJNY-2021-15).

\section{References}

Aggelides SM, Londra PA 2000. Effects of compost produced from town wastes and sewage sludge on the physical properties of a loamy and clay soil. Bioresour. Technol. 71(3): 253-259.

Bao SD 2005. Soil and Agricultural Chemistry Analysis. 3rd Ed. Beijing: China Agrice Press (in Chinese).

Chen H, Zhao Y, Feng H, Li H and Sun B 2014. Assessment of climate change impacts on soil organic carbon and crop yield based on long-term fertilization applications in Loess Plateau, China. Plant Soil. 390: $401-417$. 
Dumale Jr WA, Miyazaki T, Nishimura T and Sekik K 2009. $\mathrm{CO}_{2}$ evolution and short-term carbon turnover in stable soil organic carbon from soils applied with fresh organic matter. Geophys. Res. Lett. 36: 143153.

Ding G, Liu X, Herbert S, Novak J, Amarasiriwardena D and Xing B 2006. Effects of cover crop management on soil organic matter. Geoderma. 130: 229-239.

Egashira K, Han JL, Karim AJMS, Moslehuddin AZM, and Yamada Y 2003. Evaluation of long-term application of organic residues on accumulation of organic matter and improvement of soil chemical properties in a clay terrace soil of Bangladesh. J. Fac Agr Kyushu U. 48(1/2): 227-236.

He YT, Zhang WJ, Xu MG, Tong XG, Sun FX and Wang JZ 2015. Long-term combined chemical and manure fertilizations increase soil organic carbon and total nitrogen in aggregate fractions at three typical cropland soils in China. Sci. Total Environ. 532: 635-644.

Halen JK, Hu QC, Liu AG 2003. Compost applications increase water-stable aggregates in conventional and no-tillage systems. Soil Sci. Soc. Am. J. 67(6): 1842-1847.

Li J, Wu X, Tsegaye GM, Wu H, Cai D and Wang B 2018. Response of soil organic carbon fractions, microbial community composition and carbon mineralization to high-input fertilizer practices under an intensive agricultural system. PloS One. 4(13): e195144.

Schlegel AJ 1992. Effect of composted manure on soil chemical properties and nitrogen use by grainsorghum. J. Produc. Agr. 5(1): 153-157.

Sleutel S, Neve SD, Németh T, Tóth T and Hofman G 2006. Effect of manure and fertilizer application on the distribution of organic carbon in different soil fractions in long-term field experiments. Eur. J. Agron. 25: 280-288.

Tian K, Zhao Y, Xu X, Hai N, Huang B and Deng W 2015. Effects of long-term fertilization and residue management on soil organic carbon changes in paddy soils of China: A meta-analysis. Agric. Ecosyst. Environ. 204: 40-50.

Yousefi M, Hajabbasi M, Shariatmadari H 2008. Cropping system effects on carbohydrate content and waterstable aggregates in a calcareous soil of Central Iran. Soil Tillage Res. 1(101): 57-61.

Zhang HM, Xu MG, Zhang F 2009. Long-term effects of manure application on grain yield under different cropping systems and ecological conditions in China. J. Agr. Sci. 147(1): 31-42.

(Manuscript received on 06 July, 2021; revised on 27 September, 2021) 